\title{
Precision assembly method of a kind of small interference fitting parts
}

\author{
ZHIFENG LOU*, XINGYUAN WANG, YUE WANG, XIAODONG WANG, CHONGLIN XU and \\ ZHIZE WANG
}

Key Laboratory for Precision and Nan-Traditional Machining of Ministry of Education, Dalian University of Technology, Dalian 116023, Liaoning, China

e-mail: louzf@dlut.edu.cn

MS received 12 October 2016; revised 18 February 2019; accepted 10 April 2019; published online 22 May 2019

\begin{abstract}
Interference fitting parts are widely used in many engineering applications. Press-fit method is commonly used for assembling interference fitting parts, but most of press-fit instruments cannot meet assembly requirements of small precision parts for poor accuracies of positioning, alignment and pressing displacement's measurement. In this paper, the press-fit method of a kind of small precision interference fitting parts was introduced. In order to achieve a reasonable assembly of the interference fitting parts, the influence of aligning error and positioning error on assembly accuracies were analyzed by finite element method (FEM). Furthermore, the relation between pressing force and displacement were also analyzed to obtain a reasonable range of force-displacement curves, which can be used for assembly quality estimation. An automatic press-fit instrument was developed. Through analyzing relation between pressing force and the instrument's elastic deformation, press-fit displacement error was compensated to increase assembly accuracy. A kind of machine vision device with upper and lower CCDs was used to detect relative situation of parts, and calibration method of the machine vision device was proposed. The assembly experiments showed that press-fit force-displacement curve was consistent with the predicted values. The parts' relative position deviation was less than $\pm 5 \mu \mathrm{m}$, and parallelism deviation was less than $10 \mu \mathrm{m}$, which meet the requirements of the assembly accuracy index.
\end{abstract}

Keywords. Small part; interference fitting; press-fit instrument; alignment; assembly accuracy.

\section{Introduction}

Interference fitting can provide intimate contact between mating parts, and the parts can be held permanently as a solid component. Interference fitting parts have excellent load bearing ability under static as well as dynamic loading conditions, so it has been used in many engineering fields. The strength of such assemblies depends on various parameters such as the amount of interference, physical dimensions, material properties, surface modifications, and geometrical irregularities of mating members [1]. In this paper, assembly of two small precision parts with interference fitting was introduced, and an automatic press-fit instrument was developed according to the assembly requirements.

In order to analyze the stress distribution on the mating surface, researchers have made many achievements. Qzturk has analyzed the interfacial pressures with respect to the interferences of a two-disc shrink fit assembly by using ABAQUS/Standard [2]. The analysis result indicates that the finite-element results were in good agreement with the analytical results. If the assembly had complex shapes, the

*For correspondence finite-element method were more comprehensive and accurate. Baldanzini presented a general method for analyzing stress on contact interface between interference fitting parts, which removed restrictive limitation of material characterization and yield criterion [3]. Teng et al proposed a BP neural network calculation model for analyzing stress on interface between the two interference fitting parts, and a case analysis showed that the model was more reasonable than conventional method [4]. Yang has investigated the influence of roughness on interference value, and built a new method for computing actual interference value [5]. Sogalad has studied the influence of the average undulation number of roundness profiles on the load bearing ability of interference fitting assemblies [1].

Shrink-fit and press-fit are the main methods for assembling interference parts, and assembly processes affect parts working ability. Temperature and deformation cannot be controlled accurately, some small precision parts' assembly are usually adopted by press-fit instead of shrink-fit. In press-fit method, pressing force was used to judge assembly quality. Zhandarov has analyzed relation between pressing force and displacement through analytic method [6]. Benuzzi has proposed a simplified model for predicting relation between pressing force and displacement, and 
carried out testing methods through FEM method and experiments [7]. Huang analyzed pressing force of a bearing is assembly according to material force theory, and predicted pressing force in different key periods of assembly [8].

For small parts, assembly accuracy is an important factor affecting parts' performance, and automatic assembly technologies have been implied in precision small parts' assembly in order to ensure assembly quality. Automatic assembly instruments of small parts usually compose clamping and positioning unit, vision aligning unit, actuating unit, etc. For example, Daniel has developed automatic assembly instrument to realize the stacking of small parts based on tracking algorithm by adopting machine vision, micro gripper, etc. [9]. Zhang has investigated position and orientation measurement technology for the precision assembly of trans-scale miniature parts, and developed the automatic assembly system based on high and low magnification micro-vision units, which solved the contradiction between small field-of-view of micro-vision and large span of part feature dimension in the precision assembly of trans-scale miniature devices [10]. Das has developed multi-scale automated assembly system for the assembly of complex micro-nano parts [11]. Xu has put forward two kinds of methods of assembly (Rotating-thenpushing method and Picking-up-then-placing-down method) in micro assembly system, and improved the motion accuracy of the system and the assembly speed [12]. In general, the current studies of small parts' assembly are to control positioning accuracy or re-positioning accuracy with small assembly force. But for small precision interference fitting parts, the assembly force of press-fit method is large and most of press-fit instruments cannot be used, because of lower positioning accuracy, aligning accuracy and pressing displacement measuring accuracy. Therefore, to achieve high assembly accuracy of small interference fitting parts, the assembly method and assembly instrument should be proposed.

In the paper, the FEM was used to analyze the influence of assembly sequence and positioning error on assembly quality of small precision interference fitting parts. Based on the numerical results, an automatic press-fit instrument was developed. Furthermore, the vision alignment, accurate positioning and error compensation of press-fit displacement were also optimized to meet the assembly requirement.

\section{Assembling principle of the small interference fitting parts}

The parts to be assembled are shown in figure 1 . The interference value between the hole (the diameter is $6 \mathrm{~mm}$ ) of part A and shaft of part B is $12-14 \mu \mathrm{m}$, and the interference value between the hole of part $B$ and part $C$ is

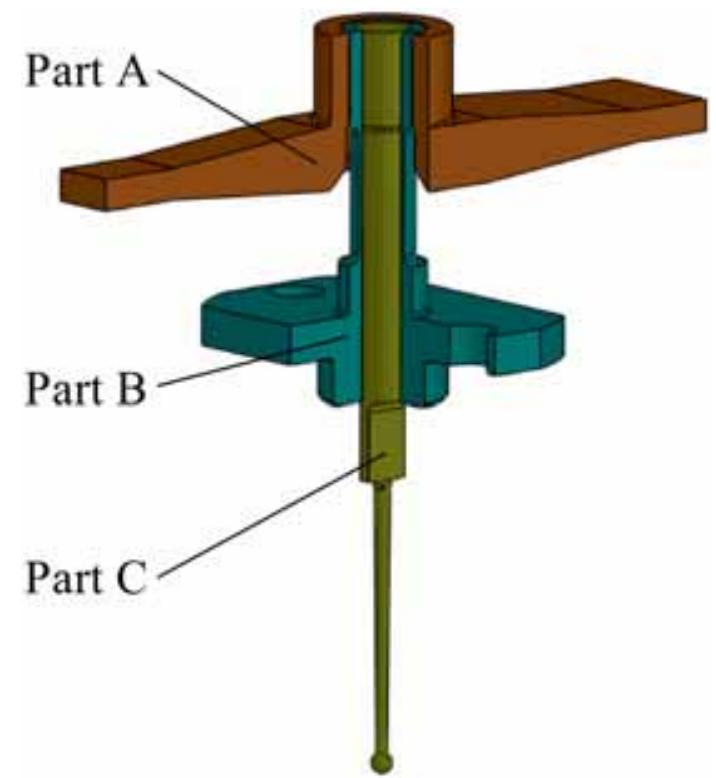

Figure 1. The parts to be assembled.

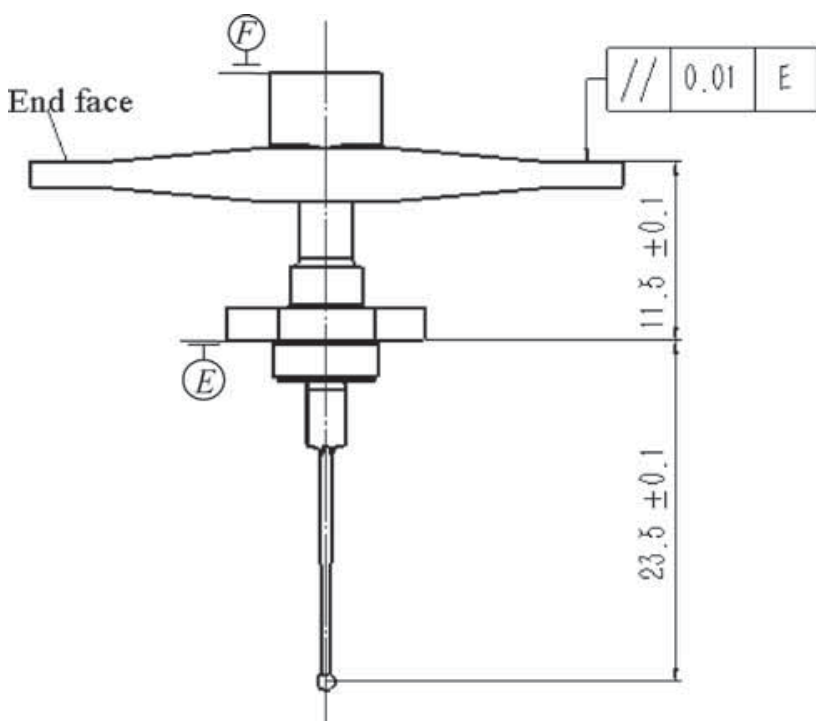

Figure 2. Assembly accuracy indexes of the three parts.

5-8 $\mu \mathrm{m}$. Assembly accuracy specification is shown in figure 2, axial assembly position deviation between two parts must be within $\pm 0.10 \mathrm{~mm}$, and parallelism deviation between two parts' end faces is within $0.01 \mathrm{~mm}$.

\subsection{Determination of reasonable range of force- displacement curves}

The finite element method (FEM) was used to determine the reasonable pressing force and displacement of the small interference parts' assembly, and the force-displacement 


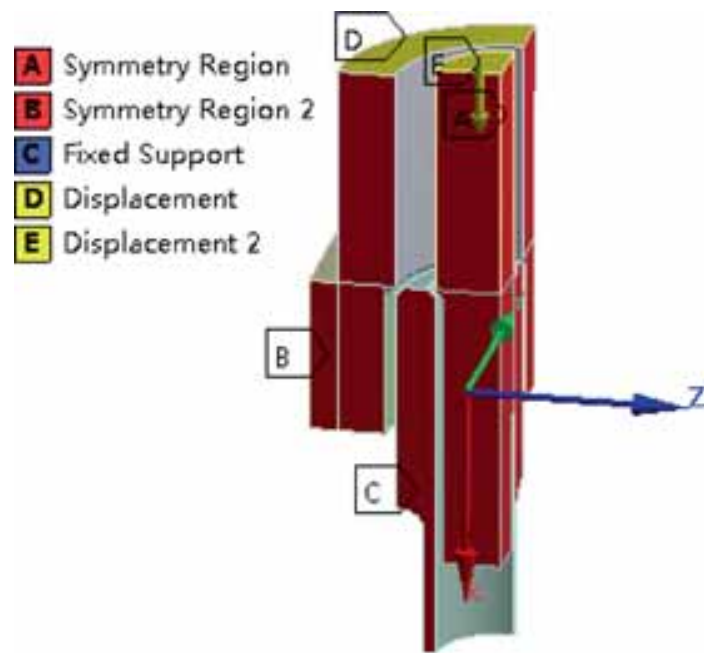

Figure 3. Simplified model and boundary conditions.

curve can be used for real-time monitoring and evaluating the assembly quality [7]. The simplified model and boundary conditions are shown in figure 3 . The contact definition is listed in table 1 [13]. The definition of interference value was achieved by setting up an offset value of the contact surface. In order to accurately analyze the stress concentration at the contact boundary, a bilinear isotropic hardening model was adopted. Part A is made of 1J50. Part $\mathrm{B}$ and part $\mathrm{C}$ are made of $3 \mathrm{~J} 1$. The mechanical properties are listed in table 2 [13].

The given interference value can ensure that only elastic deformation occurs on the contact surface, except for contact boundaries. Therefore, in the mating surfaces no plastic shear flow occurs. In this paper, the friction coefficients were calculated by pressing force (experimental results in chapter 5) and thick-walled cylinder theory [14].

Table 1. Contact definition.

\begin{tabular}{lc}
\hline Contact model & Surface to surface \\
\hline Type & Frictional \\
Coefficient of friction & 0.09 \\
Offset & Set manually \\
Behavior & Asymmetric \\
Formulation & Penalty function \\
Normal stiffness factor & Part A-Part B 2.5; Part B-Part C 3.5 \\
Element & CONTA 174 and TARGE 170 \\
\hline
\end{tabular}

To avoid the influence of resistant force, the increment of the pressing force was used [15]. Therefore, the friction coefficients of these two interfaces were calculated, and the value is 0.09 .

In order to ensure the rationality of finite element analysis, the convergence of mesh size and normal stiffness factor was analyzed. As shown in figure 4, the maximum pressing force varies less than $1 \%$ when the mesh size is less than $0.1 \mathrm{~mm}$. In order to save computational resources while ensuring computational accuracy, the mesh size is set to $0.1 \mathrm{~mm}$. As shown in figure 5 , the penetration between part A and part B remains constant when the normal stiffness factor is greater than 2, so the normal stiffness factor is set to 2.5. Similarly, the normal stiffness factor between part $B$ and part $C$ is 3.5 . In order to prove the validity of the finite element model, 3 sets of assembly experiments were performed in the sequence that part A first assembly. The interference value between parts $\mathrm{A}-\mathrm{B}$ and $\mathrm{B}-\mathrm{C}$ is 12 and $5 \mu \mathrm{m}$, respectively. As shown in figure 6, the numerical results are in good agreement with experimental results, and the small deviation may be caused by the form error of the contact surface.

In order to determine the optimal assembly sequence, two assembly sequences were analyzed: one is to assemble part A first (A-C), and the other is part C first (C-A). As shown in figure 7 , the assembly sequence has a great influence on pressing force, so does the stress distribution.

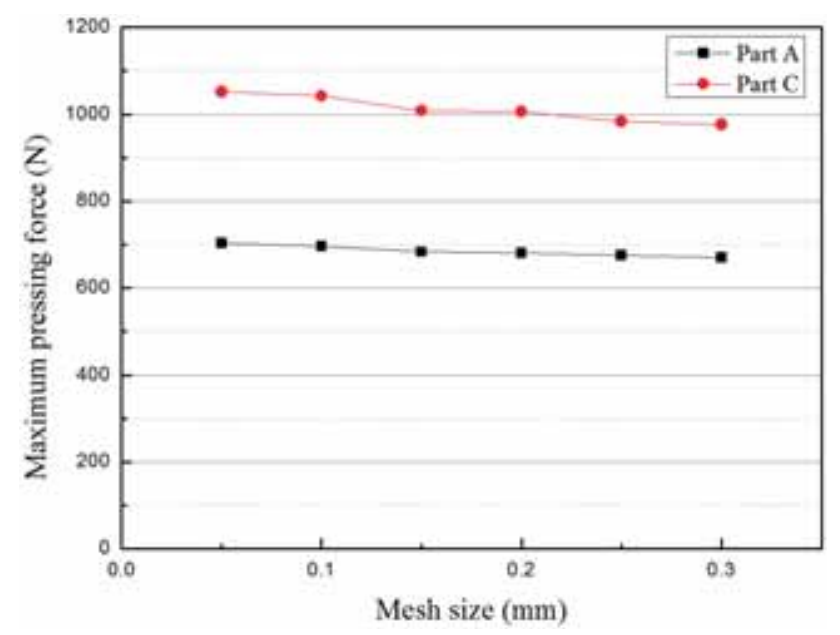

Figure 4. Maximum pressing force versus mesh size.

Table 2. Materials' properties.

\begin{tabular}{lccccr}
\hline Material & Density $\left(\mathrm{kg} / \mathrm{m}^{3}\right)$ & Young's modulus $(\mathrm{GPa})$ & Poisson's ratio & Yield strength (MPa) & Tangential modulus (MPa) \\
\hline 1J50(50Ni-50Fe) & 8200 & 157 & 0.34 & 686 & 942 \\
$3 \mathrm{~J} 1$ (Ni36CrTiAl) & 8000 & 186 & 0.3 & 882 & 1116 \\
\hline
\end{tabular}




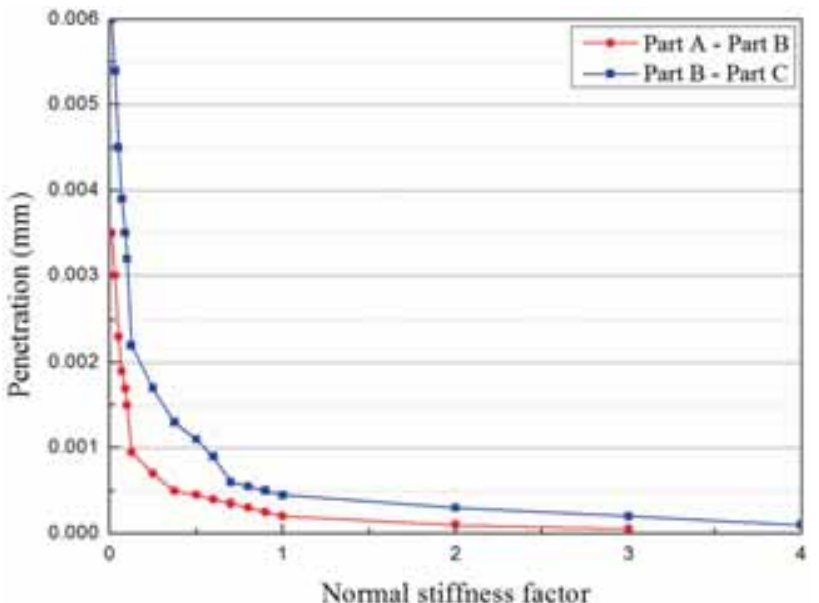

Figure 5. Penetration versus normal stiffness factor.

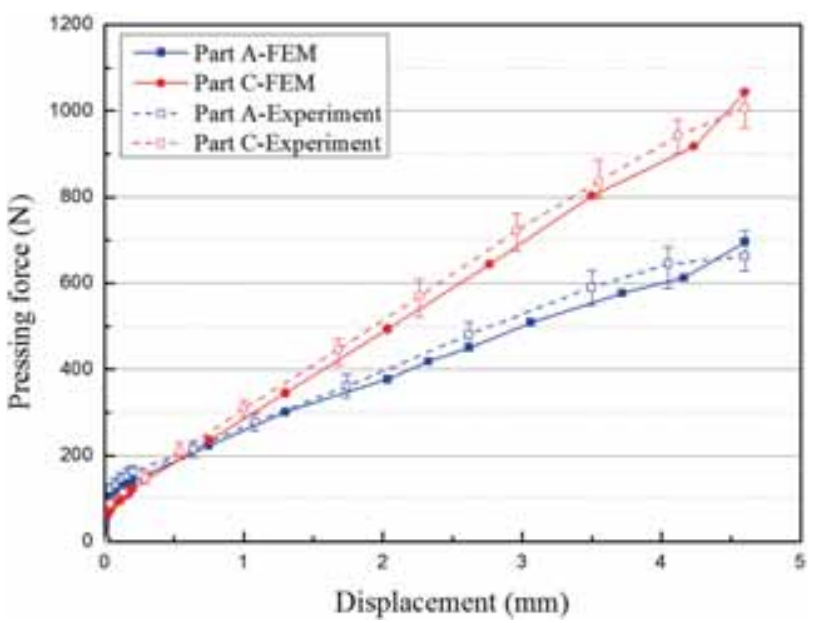

Figure 6. Validation of numerical results.

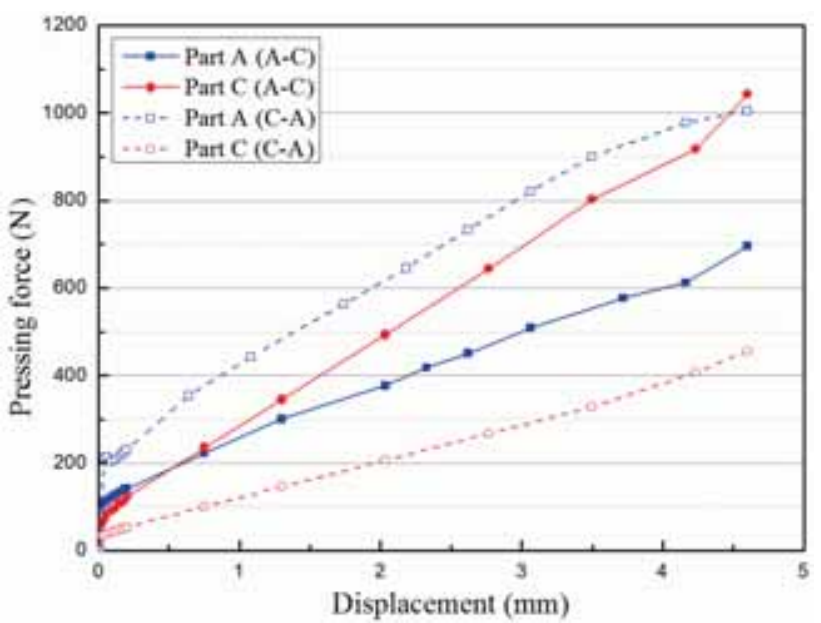

Figure 7. The influence of assembly sequence on pressing force (interference value: part A-B $12 \mu \mathrm{m}$, part B-C $5 \mu \mathrm{m}$ ).

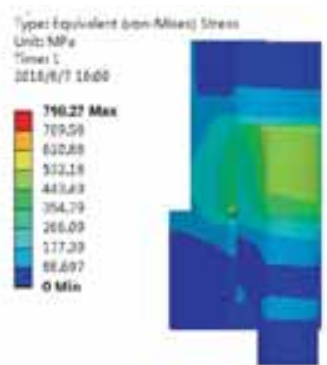

(a)

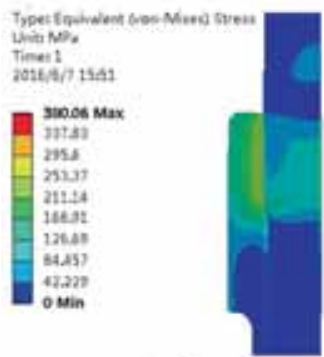

(c)
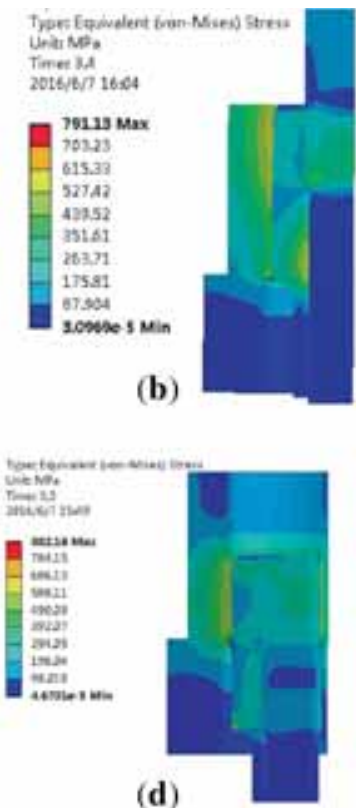

Figure 8. The influence of assembly sequence on stress distribution: A-C sequence (a) to (b); C-A sequence (c) to (d).

Therefore, the stress distribution under different assembly sequences was analyzed (see figure 8). Obviously, the equivalent stress of the contact surface of part $\mathrm{A}$ in A-C sequence is nearly $360 \mathrm{MPa}$ which is much smaller than $680 \mathrm{MPa}$ in $\mathrm{C}-\mathrm{A}$ sequence. In order to avoid wearing and increase assembly quality, A-C sequence was adopted to assemble the components.

Finally, the reasonable range of force-displacement curves of part $\mathrm{A}$ and part $\mathrm{C}$ were obtained, and the results are shown in figures 9 and 10, respectively.

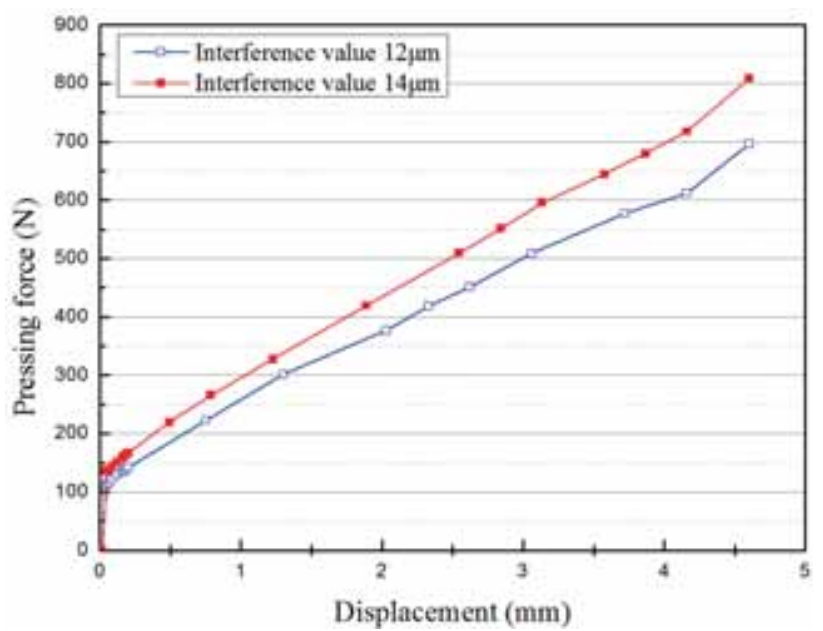

Figure 9. The reasonable range of force-displacement curves of part A. 


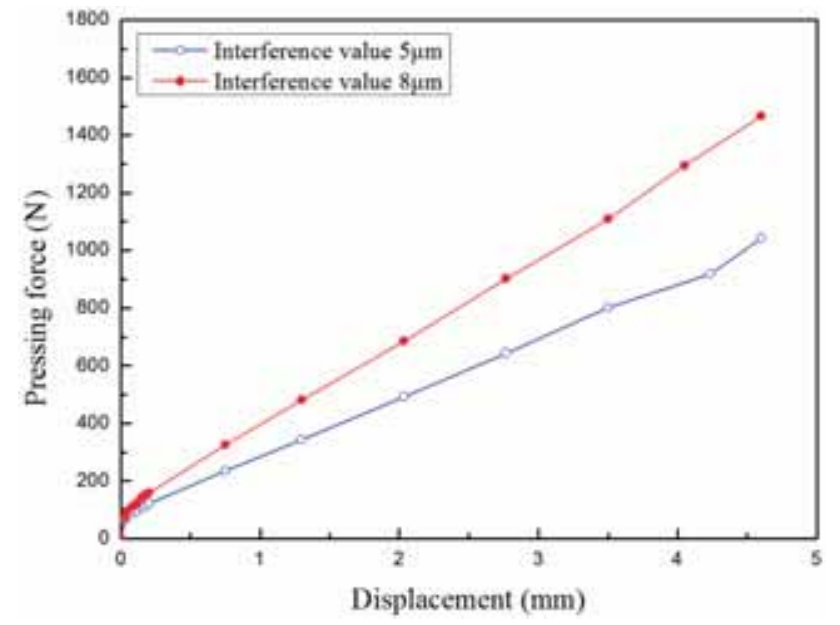

Figure 10. The reasonable range of force-displacement curves of part C.

\subsection{Assembly accuracy simulation}

Positioning errors in assembly are important factors affecting assembly accuracy. Therefore, parallelism deviation between the two parts' end face resulted from alignment error and yaw positioning error were analyzed.

2.2a Aligning error of the two parts: In order to assemble parts accurately, the hole of part A and the shaft of part B must be aligned accurately, so the influence of aligning error on assembly accuracy was simulated by FEM. Figure 11 shows the stress cloud of the two parts with different contact lengths with an alignment error $0.01 \mathrm{~mm}$. The analysis results showed that the effect of aligning error on contact stress is negligible, and the parallelism deviation between the two parts' end faces was $0.65 \mu \mathrm{m}$ which can also be neglected. Therefore the small alignment error has small influence on assembly accuracy for the guide function of the chamfer of part B.
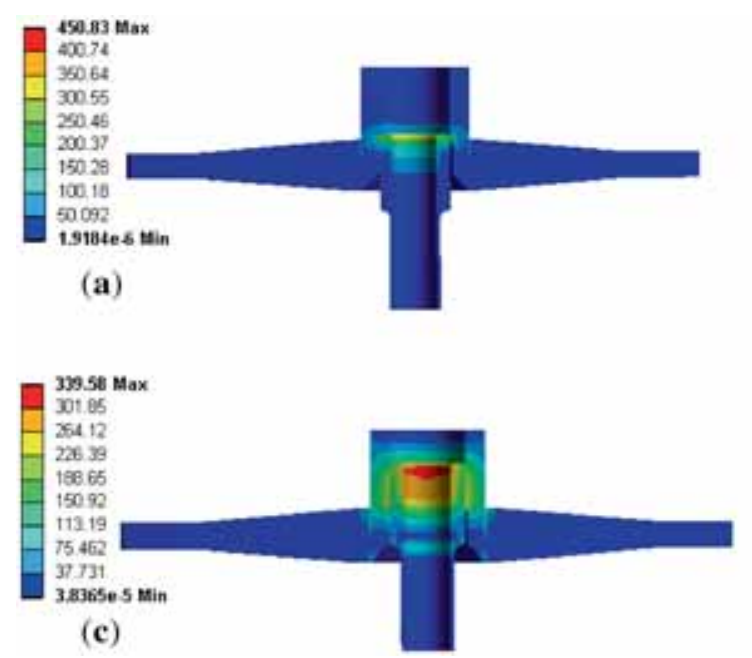

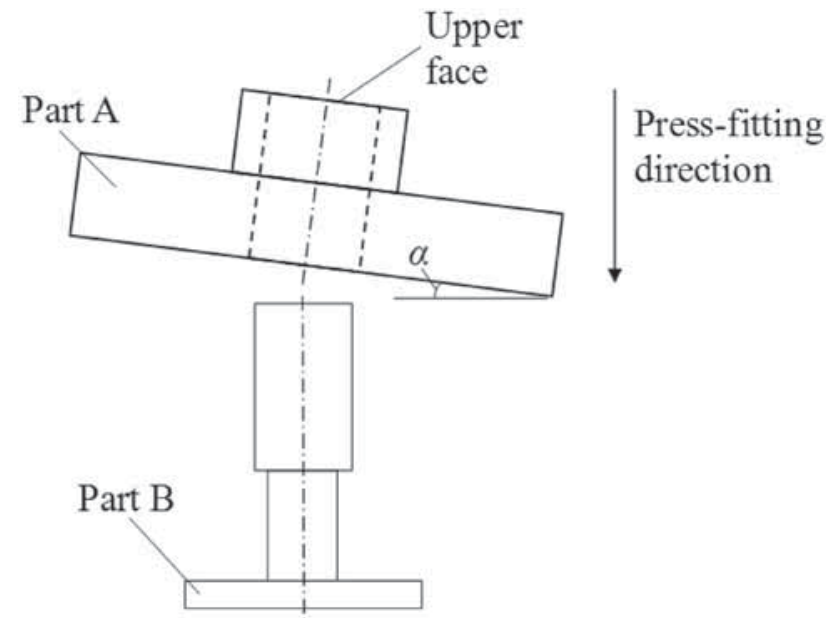

Figure 12. Yaw positioning error of part A.

2.2b Yaw positioning error of Part A: As shown in figure 12, a yaw angle will be generated between axis of part $\mathrm{A}$ and press-fit direction if the position face incline to reference face. Therefore, FEM was used to analyze parallelism deviation according to different yaw angles. As shown in figure 13, the parallelism deviations with different yaw angles were obtained (interference value $12 \mu \mathrm{m}$ ). Obviously, in order to ensure assembly accuracy, the yaw angle $\alpha$ must be less than $0.03^{\circ}$. The stress cloud with the yaw angle $0.03^{\circ}$ is shown in figure 14. Clearly, the contact surfaces are all less than the yield stress, which indicates that no plastic deformation occurred in the assembly process.

Since the interference value also affects the parallelism deviation when yaw angle exists, the influence of interference value was analyzed, and the results are shown in figure 15. The results show that the parallelism deviation increases with the increase of interference value. This may be due to the fact that the two parts have a coaxial recovery
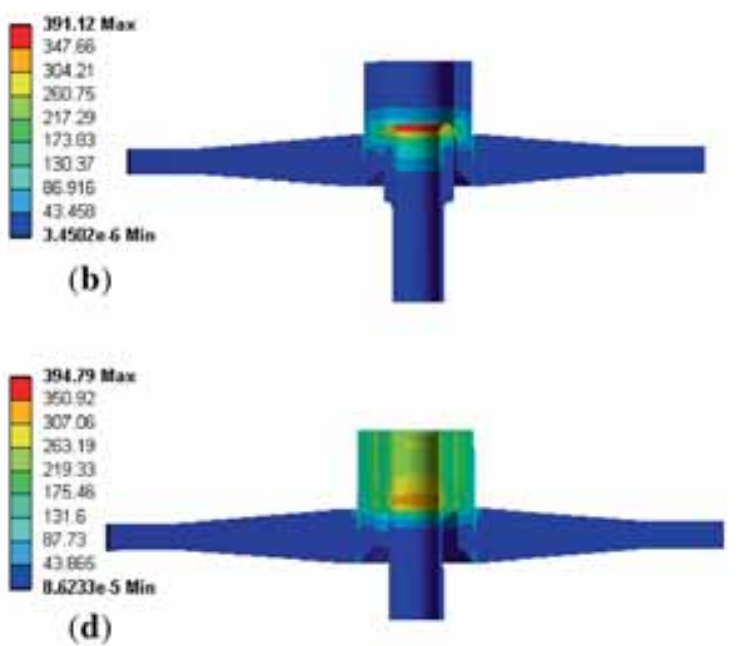

Figure 11. The stress cloud of the two parts with different contact lengths: (a) $0.12 \mathrm{~mm}$, (b) $0.48 \mathrm{~mm}$, (c) $2.5 \mathrm{~mm}$, (d) $4.4 \mathrm{~mm}$. 


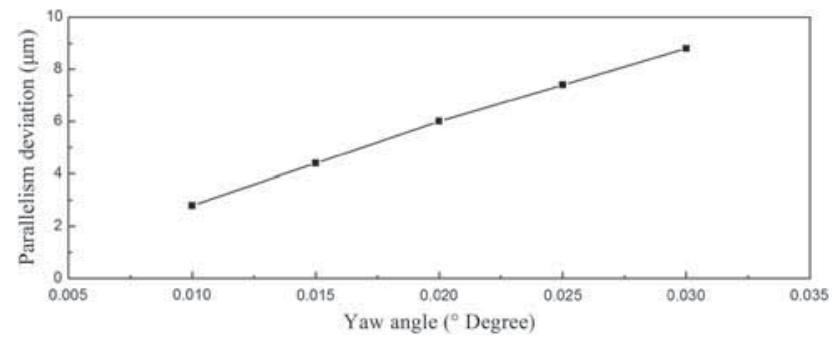

Figure 13. Parallelism deviation with different yaw angles (interference value is $12 \mathrm{um}$ ).

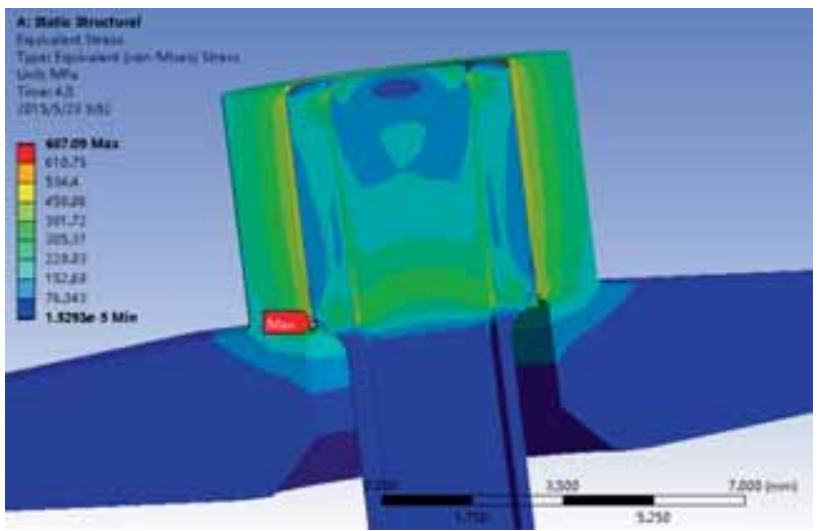

Figure 14. Stress distribution cloud with yaw angle $0.03^{\circ}$.

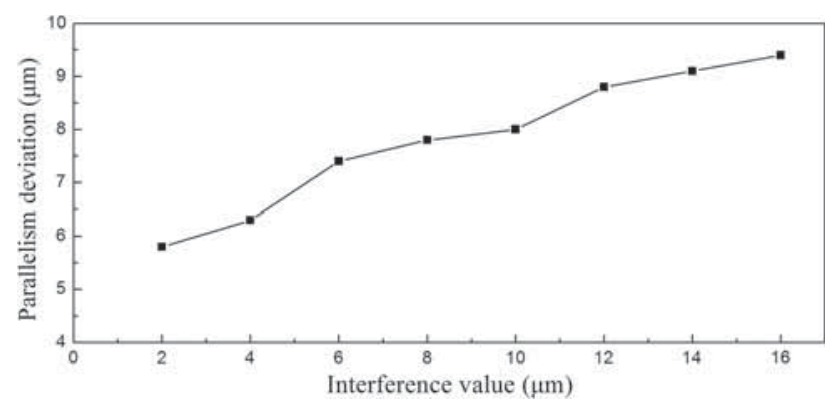

Figure 15. Parallelism deviation according to different interference values (yaw angle $0.03^{\circ}$ ).

tendency when there is a positional deviation during the press-fit process, but the recovery resistance increases as the interference value increases.

\section{Precision press-fit instrument for assembling small parts}

In order to assemble the parts accurately, a precision pressfit instrument was developed (see figure 16). The instrument is mainly composed of main frame, parts' relative position measuring unit, the upper and lower fixtures, and $\mathrm{XY}$ precision guide, etc. The main frame is based on 4

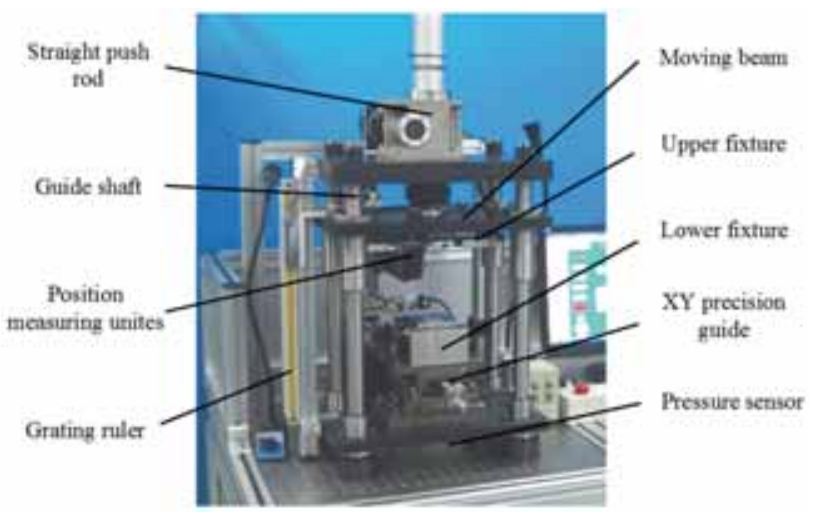

Figure 16. The precision press-fit instrument.

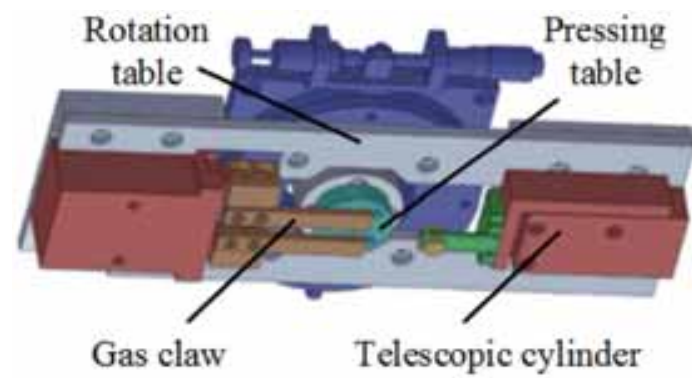

Figure 17. The upper fixture for positioning part.

guide shafts, and consists of a pressure sensor and a grating ruler, which are used to measure pressing force and displacement, respectively. The straight push rod drives moving beam to move up and down, and applies force on the parts.

The upper fixture is shown in figure 17, and part $\mathrm{A}$ is clamped by a gas claw. Because of sizes' limitation of the parts, press-fit process includes two pressing steps, and the second press-fit step was finished by a telescopic cylinder.

The structure of the lower fixture is shown in figure 18 . Two moving plates are mounted on the two rails, and these two plates can drive two semi positioning discs to separate and close so that the positioning of part B can be achieved. The lower end of Part B is clamped by a gas clip to prevent it from moving in axial direction.

As shown in figure 19, Parts' position measuring unit is consisted of two high precision CCDs and three precision guides, which is used to measure the relative positions of two parts to be assembled. The rotation table on the upper fixture and the XY precision guides are used to adjust parts' relative position.

The press-fit process is as follows. Firstly, each part of the instrument returns to the initial position and the upper and lower fixture open. Part A and part B are mounted on upper and lower fixture, respectively. The parts' position 

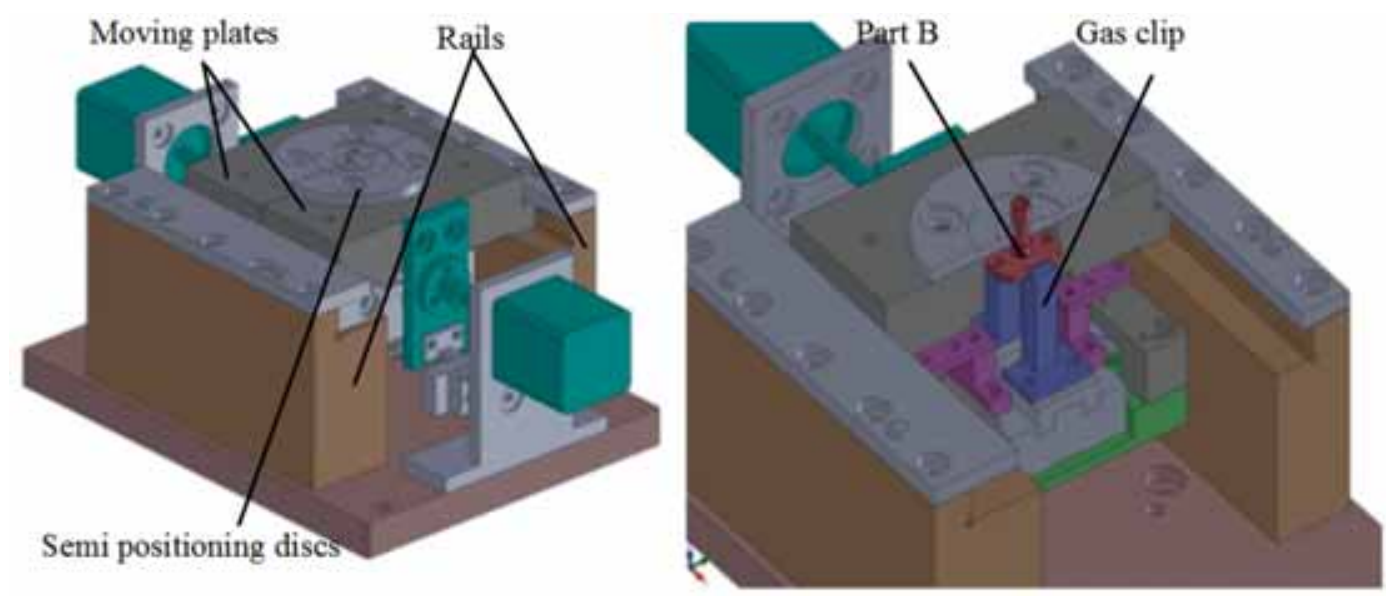

Figure 18. The lower fixture for positioning part.

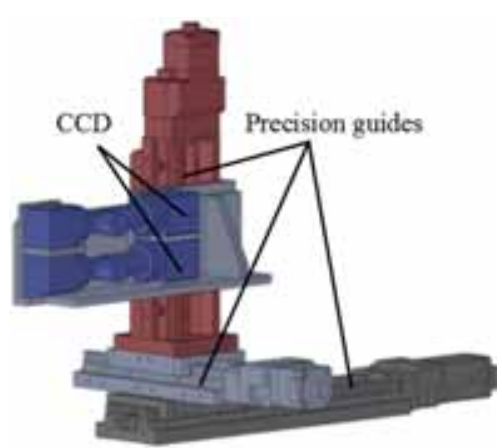

Figure 19. Parts' position measuring unit.

measuring unit moves to the predetermined position to measure the relative position and attitude between part $\mathrm{A}$ and Part B. The rotation table and XY precision guides adjust the position and attitude deviation. Finally, the moving beam moves down and presses part A into Part B. Part $\mathrm{C}$ can be assembled using the same steps described above.

\section{Key techniques of the press-fit instrument}

According to accuracy requirements, axial relative position deviation and parallelism deviation between the two parts are key accuracy indexes. Therefore, the press-fit displacement and position measuring unit were analyzed.

\subsection{Error compensation of press-fit displacement}

The instrument structure has elastic deformation when the small parts are being pressed. Each part's deformation of the instrument can be analyzed by FEM method. As shown in figure 20, the instrument was simplified into a model and

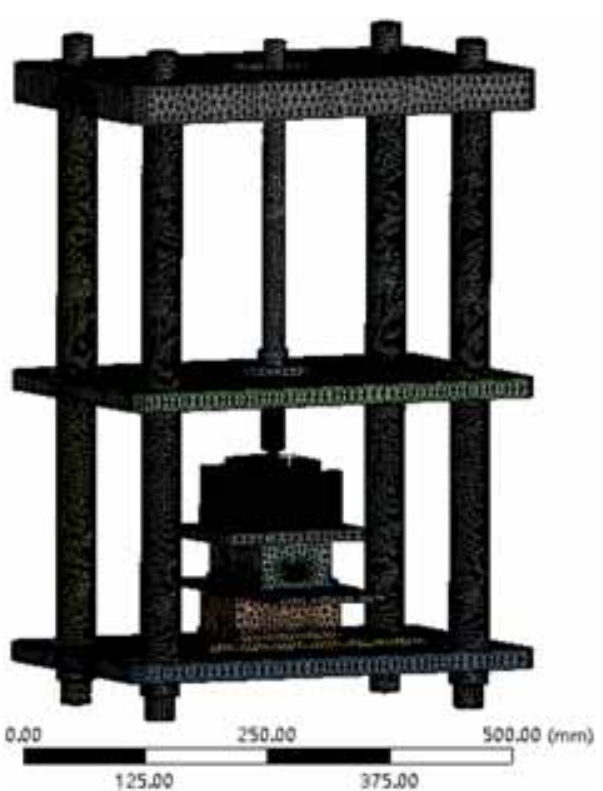

Figure 20. Instrument's simplified model.

divided into grids. A $2000 \mathrm{~N}$ pressing force was applied on the instrument, and the deformation of each part was computed. According to analysis, the deformation of pressing table and semi position discs were $5 \mu \mathrm{m}$ and $16 \mu \mathrm{m}$, respectively, as shown in figures 21 and 22. The total deformation of the instrument will be $30 \mu \mathrm{m}$ under $200 \mathrm{~kg}$ pressing force. The result shows that elastic deformation of the instrument will affect assembly accuracy of small parts, and should be compensated.

Experiments were carried out to measure the deformation. In experiments, the lower fixture was pressed directly by the pressing table. Deformation under different pressing forces was measured by grating ruler, and the results are larger than the numerical results, which may be caused by 

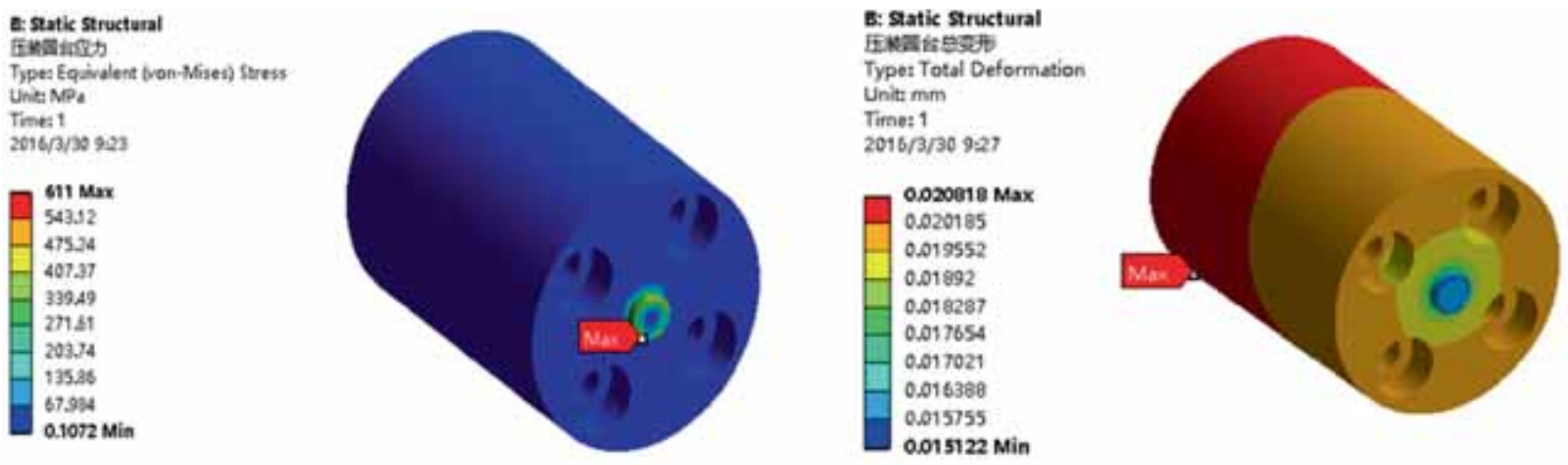

(a)

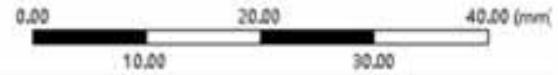

(b)

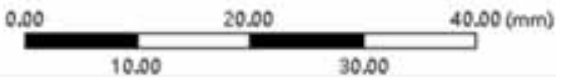

Figure 21. Stress cloud and deformation of pressing table: Stress cloud diagram (a), Deformation diagram (b).

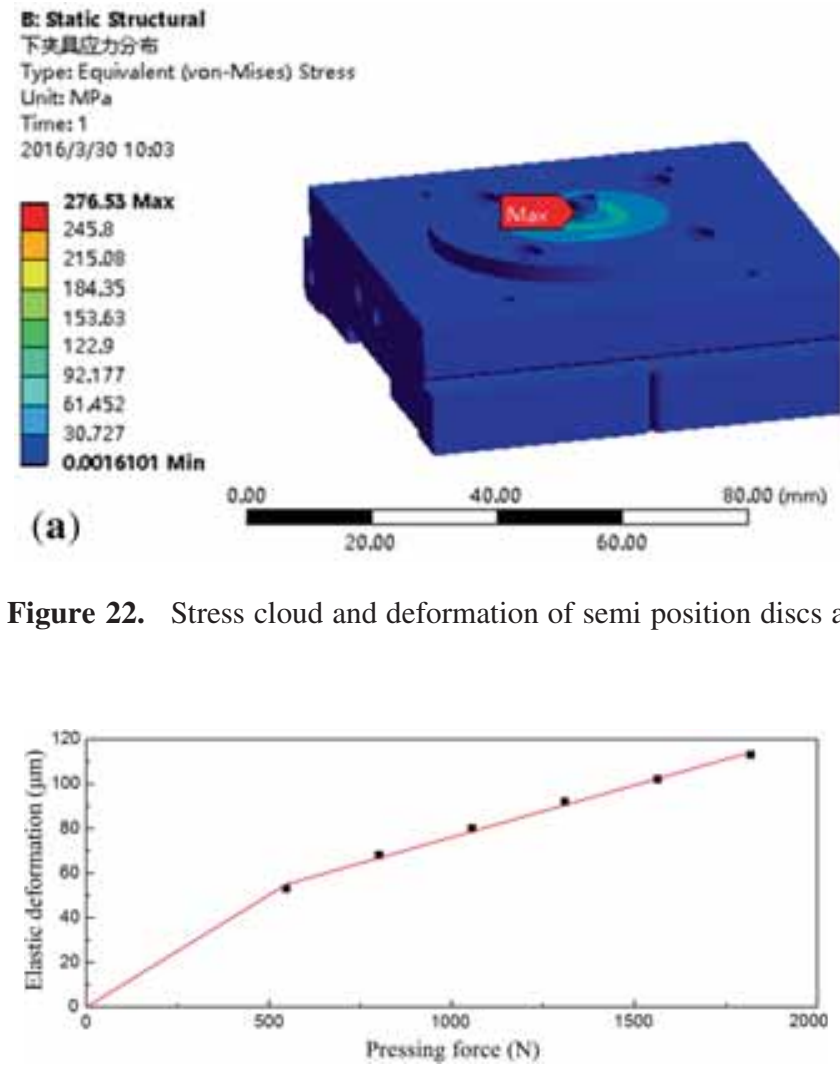

Figure 23. Elastic deformation versus pressing force.

the machining error of components. The relationship curve between elastic deformation and pressing force is shown in figure 23, and the curve was fitted as Eq. (1). In order to ensure the axial position accuracy, the elastic deformation in press fitting should be compensated according to Eq. (1).

$$
d_{\mathrm{e}}= \begin{cases}0.1005 F & 0<F<548 \\ 0.0492 F+25.86 & F>548\end{cases}
$$

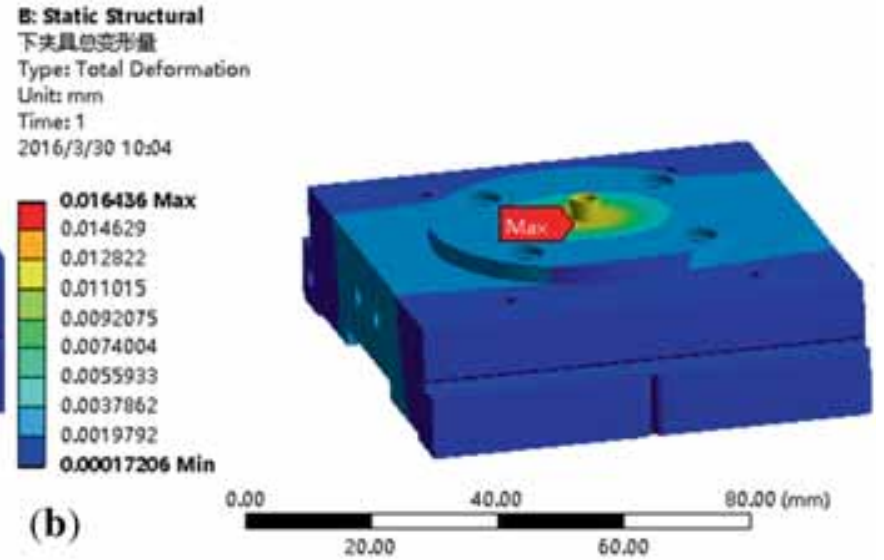

(b)
In Eq. (1), $F$ is pressing force $(\mathrm{N}), d_{e}$ is elastic deformation value $(\mu \mathrm{m})$.

\subsection{Calibration of position measuring unit}

The parts' position measuring unit has an upper CCD and a lower CCD (SENTECH, STC-MB202USB), which can acquire the images of the parts through the reflectors (figure 24). The parameters of the CCD are listed in table 3. The alignment process is shown in figure 25. Firstly, the images of the parts were acquired through the two CCDs. Then the relative position and attitude between the two parts can be obtained by image processing (NI Vision Assistant). Finally, the relative position and attitude of the two parts can be adjusted.

In order to achieve high aligning accuracy, the relative position of the two CCDs should be calibrated. The coordinate systems of the two CCDs can be united through rotation and translation. If the relative position between the two CCDs and the coordinates of one common point in the 


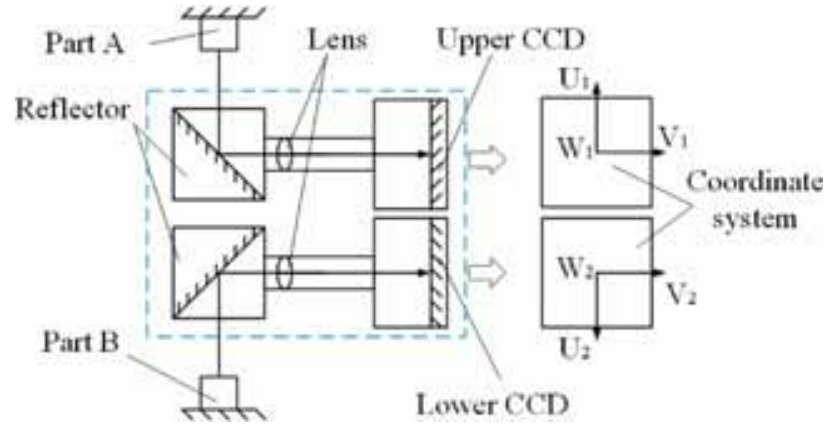

Figure 24. Coordinate system of the upper and lower CCD.

Table 3. CCD parameters.

\begin{tabular}{lcccc}
\hline $\begin{array}{l}\text { Resolution } \\
(\text { pixel })\end{array}$ & $\begin{array}{c}\text { Frame } \\
\text { rate }(\mathrm{fps})\end{array}$ & $\begin{array}{c}\text { Image } \\
\text { sensor }\end{array}$ & $\begin{array}{c}\text { Depth of } \\
\text { field }(\mu \mathrm{m})\end{array}$ & $\begin{array}{c}\text { Field of view } \\
(\mathrm{mm})\end{array}$ \\
\hline $1600 \times 1200$ & 15 & $1 / 1.8^{\prime \prime}$ & 270 & $5.4 \times 7.1 \times 8.9$ \\
\hline
\end{tabular}

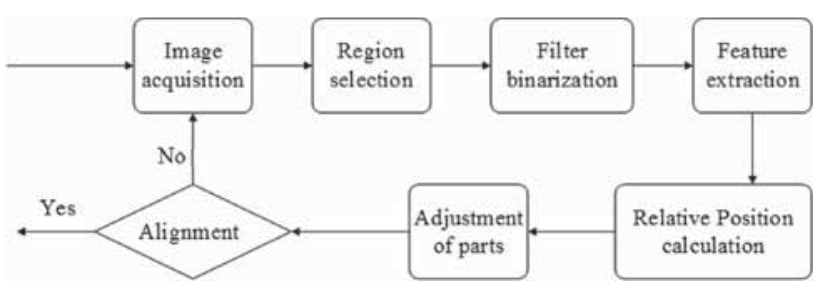

Figure 25. Alignment process.

two CCDs can be determined, the coordinate transformation equation between the two CCDs can be determined. Therefore, the calibration of the CCDs relative position is the key to achieve precise alignment.
The coordinate transformation equation was obtained by translating and rotating the upper camera coordinates.

$$
\begin{aligned}
& {\left[\begin{array}{ccc}
\mathrm{S}_{\mathrm{u} 1} & 0 & 0 \\
0 & \mathrm{~S}_{\mathrm{v} 1} & 0 \\
0 & 0 & 1
\end{array}\right]\left[\begin{array}{c}
1600-u_{1} \\
v_{1} \\
1
\end{array}\right]} \\
& =\left[\begin{array}{ccc}
1 & 0 & D_{x} \\
0 & 1 & D_{y} \\
0 & 0 & 1
\end{array}\right]\left[\begin{array}{ccc}
\cos \gamma & -\sin \gamma & 0 \\
\sin \gamma & \cos \gamma & 0 \\
0 & 0 & 1
\end{array}\right]\left[\begin{array}{ccc}
S_{u 2} & 0 & 0 \\
0 & S_{v 1} & 0 \\
0 & 0 & 1
\end{array}\right]\left[\begin{array}{c}
u_{2} \\
v_{2} \\
1
\end{array}\right]
\end{aligned}
$$

Where, $S_{u i}$ and $S_{v i}(i=1,2)$ are the physical sizes of one pixel of the two CCDs in the $\mathrm{U}$ and $\mathrm{V}$ directions; $\mathrm{D}_{\mathrm{x}}$ and $\mathrm{D}_{\mathrm{y}}$ are the parameters for coordinate system translation; $\gamma$ is deflection angle between the coordinate axes of the two CCDs; $u_{i}$ and $v_{i}$ are coordinate values of the common point in the two CCDs.

The parameters in Eq. (2) can be computed according to following method.

Firstly, the pixel size of these two CCDs was calibrated using an optical standard ruler. For example, when calibrate the lower CCD, the optical standard ruler was attached on a precision turntable which was mounted on the lower fixture (see figure 26(a)). Then, the image was obtained when the optical standard ruler was parallel and perpendicular to the lower CCD's V $\mathrm{V}_{2}$-axis (see figure 26(d) and (e)). Finally, the pixel size in $\mathrm{U}_{2}$ and $\mathrm{V}_{2}$ directions can be calculated by image processing. The pixel size of the upper CCD can be obtained in the same way. The calibration results are listed in table 4.

Secondly, deflection angle between the two CCD coordinate axes was calibrated.

As shown in figure 27, coordinate systems existing in the vision alignment device are image coordinate systems of the two CCDs $\left(\mathrm{U}_{\mathrm{i}} \mathrm{V}_{\mathrm{i}} \mathrm{W}_{\mathrm{i}}, \mathrm{i}=1,2\right)$. And the world coordinate
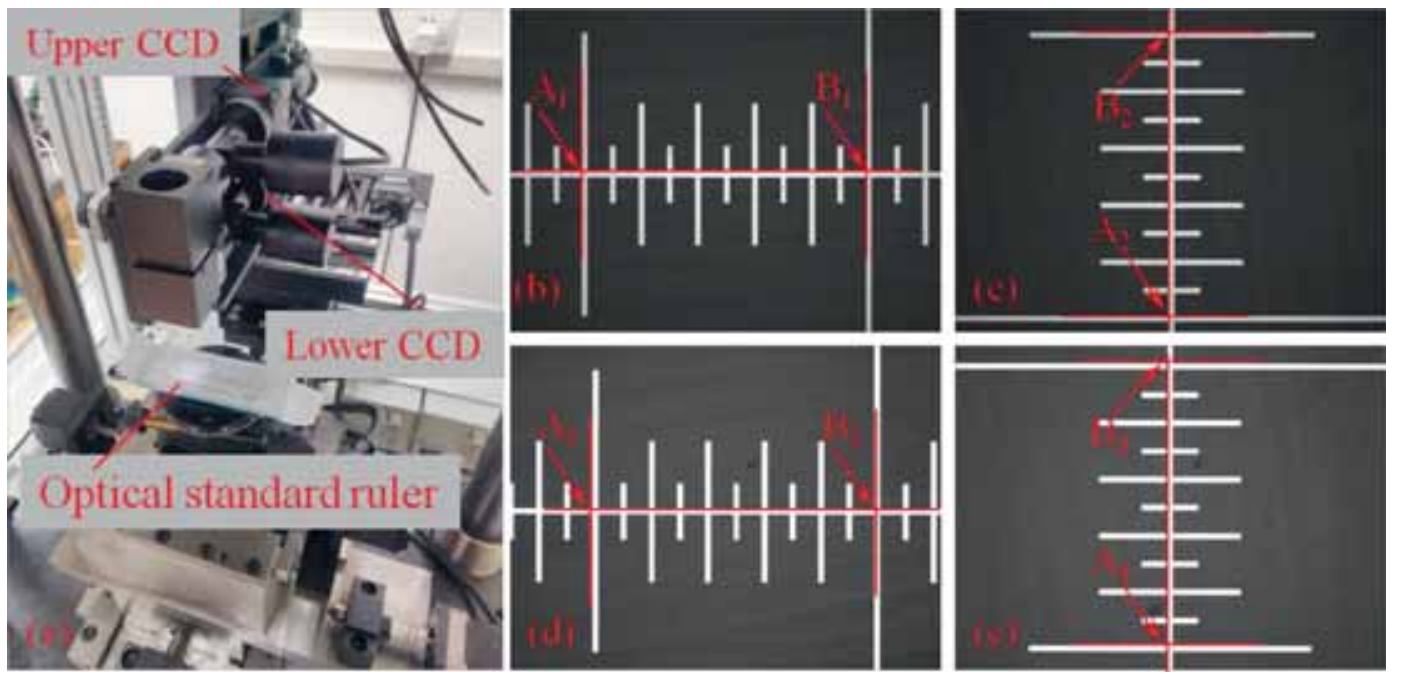

Figure 26. Calibration of the pixel size of upper and lower CCD (a), images of the upper CCD (b) and (c), images of the lower CCD (d) and (e). 
Table 4. Pixel size of upper and lower CCD.

\begin{tabular}{lcc}
\hline & $\mathrm{S}_{u i}(\mu \mathrm{m} /$ pixel $)$ & $\mathrm{S}_{v i}(\mu \mathrm{m} /$ pixel $)$ \\
\hline $\mathrm{i}=1$ & 4.31 & 4.33 \\
$\mathrm{i}=2$ & 4.42 & 4.41 \\
\hline
\end{tabular}

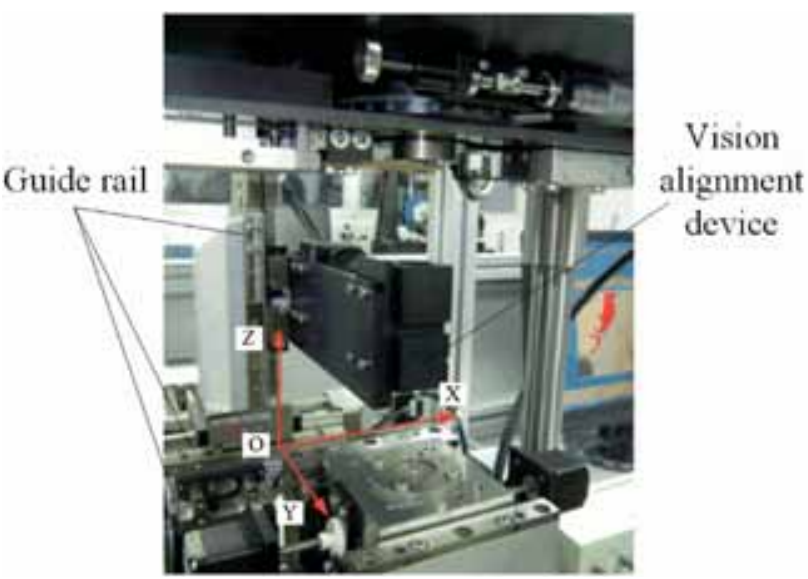

Figure 27. Machine vision alignment device.

system XYZ is composed of guide rails. If deflection angles between two CCDs coordinate systems and global coordinate system can be computed, the deflection angle between the two CCDs' coordinate system can be acquired. Position calibration method of the upper and lower CCD is shown in figure 28. A standard ruler was fixed on the lower fixture and adjusted parallel with $\mathrm{U}_{2}$ axis of the lower CCD. The ruler's image was acquired by the lower $\mathrm{CCD}$, and point 1's coordinate value in $\mathrm{U}_{2} \mathrm{~W}_{2} \mathrm{~V}_{2}$ is $\left(\mathrm{u}_{21}, \mathrm{v}_{21}\right)$. CCD moved along $\mathrm{Y}$ axis, and distance is $l_{12}$. Coordinate system move to $\mathrm{U}_{2}{ }^{\prime} \mathrm{W}_{2}{ }^{\prime} \mathrm{V}_{2}$ ', and point 2's coordinate value in the lower CCD is $\left(\mathrm{u}_{22}, \mathrm{v}_{22}\right)$. The following equation can be acquired.

$$
\tan \gamma_{2}=\frac{S_{v 2} \cdot\left(v_{22}-v_{21}\right)}{l_{12}}
$$

In equation, $\gamma_{2}$ is deflection angle between the lower CCD coordinate system and global coordinate system.

According to same principle, deflection angle between the upper CCD coordinate system and global coordinate system $\left(\gamma_{1}\right)$ can also be acquired. So deflection angle between the two CCDs is

$$
\gamma=\gamma_{1}-\gamma_{2}
$$

In the instrument, $\gamma_{1}$ is $0.30^{\circ}$, and $\gamma_{2}$ is $-0.43^{\circ}$.

Thirdly, $\mathrm{D}_{\mathrm{x}}$ and $\mathrm{D}_{\mathrm{y}}$ were computed. A rectangular aluminum block was fixed on the lower fixture, and then the moving beam moved down (figure 29). The round head of the upper fixture pressed on the aluminum block, and a circular pattern was produced. Then the moving beam returned to the initial position, where the part A was

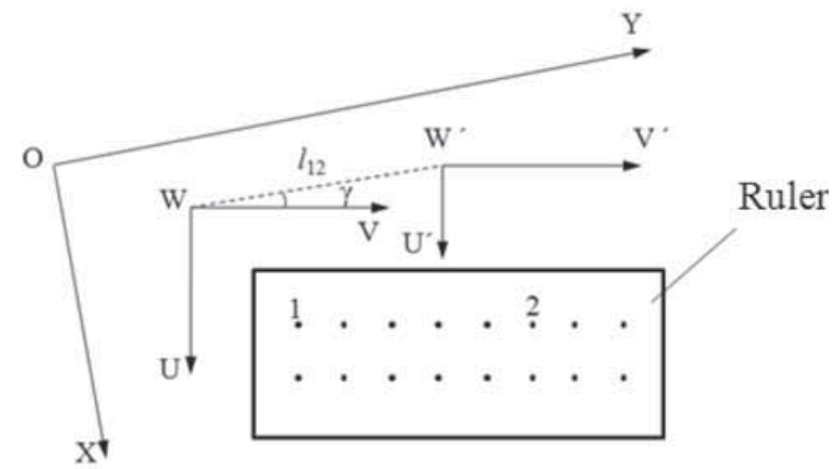

Figure 28. Position calibration of the upper and lower CCD.

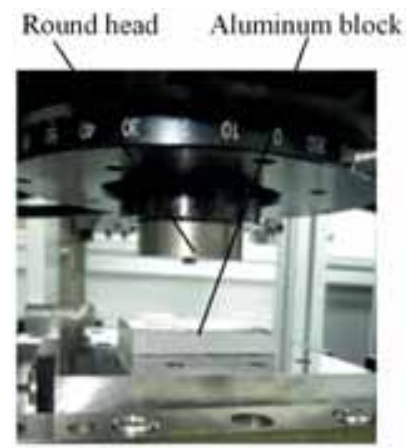

Figure 29. Computation method of $\mathrm{D}_{x}$ and $\mathrm{D}_{y}$.

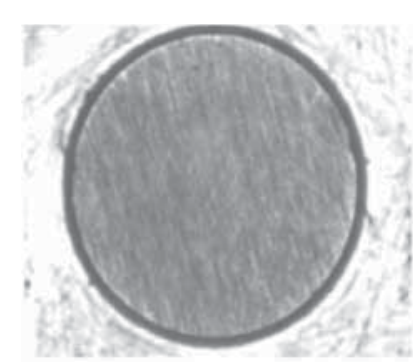

(a)

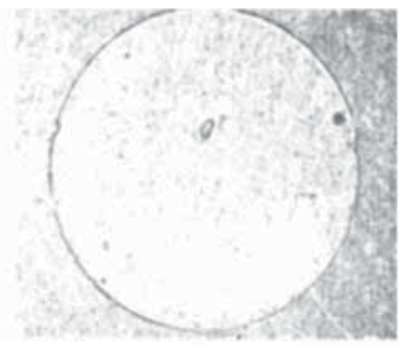

(b)
Figure 30. The image of the round head and the pattern: (a) round head, (b) pattern.

mounted on the upper fixture, and the circular pattern's position was same as the initial position of part B. The CCDs acquired images of the round head and circular pattern (figure 30), and the centers of the images were obtained. According to experiments, the round head and the pattern images' center coordinates in the two CCDs were (807.7, 584.4) and $(687.3,511.6)$, respectively. We substituted the images' center coordinates into Eq. (2), so that $D_{x}$ and $D_{y}$ were computed as 405.9383 and $235.775 \mu \mathrm{m}$, respectively.

The coordinate relationship equation of images acquired by the two CCDs is as follows. 
Table 5. Analysis of alignment error.

\begin{tabular}{llllll}
\hline Round head (pixel) & $(626.04,767.35)$ & $(630.63,760.43)$ & $(763.64,903.24)$ & $(703.67,752.53)$ & $(688.90,783.88)$ \\
Pattern (pixel) & $(866.71,688.95)$ & $(862.15,682.22)$ & $(734.56,823.75)$ & $(790.83,675.37)$ & $(805.63,706.26)$ \\
Transferred (pixel) & $(868.39,688.94)$ & $(863.85,682.20)$ & $(736.32,824.06)$ & $(792.54,675.65)$ & $(807.53,705.95)$ \\
Alignment error $(\mu \mathrm{m})$ & $(-7.43,0.04)$ & $(-7.53,0.07)$ & $(-7.77,-1.39)$ & $(-7.55,-1.24)$ & $(-8.41,1.37)$ \\
\hline
\end{tabular}

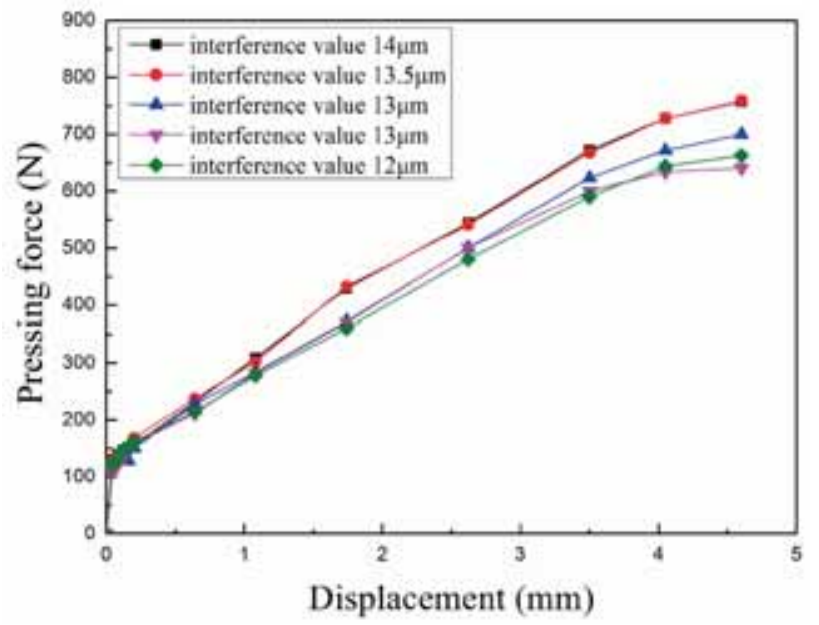

Figure 31. Pressing force and displacement curve of part A.

$$
\left\{\begin{array}{l}
\mathrm{u}_{2}=-0.9712 u_{1}+0.0115 v_{1}+1467.577 \\
v_{2}=0.0124 u_{1}+0.9818 v_{1}-72.2056
\end{array}\right.
$$

In Eq. (5), $u_{i}, v_{i}(i=1,2)$ are coordinate values of the images' point in the upper and lower CCD, and the unit is pixel.

Position deviation between part A and part B was computed through analyzing images acquired by the CCDs according to Eq. (5), and were adjusted by XY precision guide.

In order to verify the measurement accuracy of the position measuring unit, the imprint method was used for verification. The results are shown in table 5. Obviously, the alignment error is less than $10 \mu \mathrm{m}$, so the calibration method proposed in this paper is very effective.

\section{Press-fit experiments}

To analyze the assembly accuracy of the instruments, assembly experiments were carried out. In this experiment, 5 sets of parts were assembled, and the force-displacement curves are shown in figures 31 and 32. Obviously, all the curves are within the reasonable range. Parts assembly accuracies are shown in table 6 . The results show that all the accuracy indexes are superior to assembly accuracy requirements.

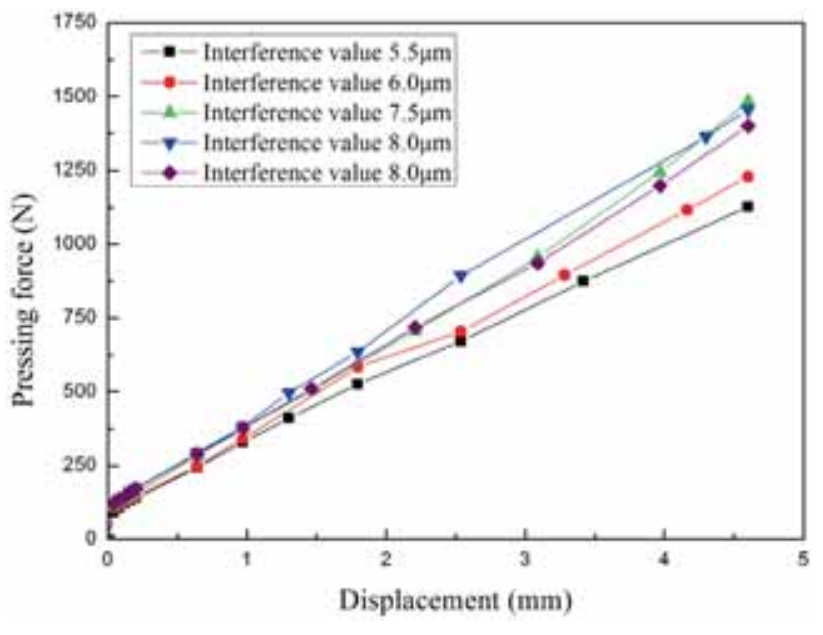

Figure 32. Pressing force and displacement curve of part C.

Table 6. Assembly accuracies' detection results.

\begin{tabular}{lccc}
\hline No. & $\begin{array}{c}\text { Parallelism } \\
\text { deviation of part A } \\
(\mu \mathrm{m})\end{array}$ & $\begin{array}{c}\text { Assembly } \\
\text { distance of part A } \\
(\mathrm{mm})\end{array}$ & $\begin{array}{c}\text { Assembly } \\
\text { distance of part C } \\
(\mathrm{mm})\end{array}$ \\
\hline 1 & 8 & 11.533 & 23.500 \\
2 & 6 & 11.521 & 23.500 \\
3 & 8 & 11.530 & 23.503 \\
4 & 8 & 11.507 & 23.510 \\
5 & 4 & 11.533 & 23.517 \\
\hline
\end{tabular}

\section{Conclusion}

In this paper, the precision assembly method of small interference fitting parts was analyzed in detail. To reduce the surface wear in assembly process, two different assembly sequences were analyzed by FEM. The results show that the equivalent stress in $\mathrm{A}-\mathrm{C}$ sequence is almost half of $\mathrm{C}$-A sequence. Therefore, part A first assembly was determined.

The reasonable range of force-displacement curves, the influence of aligning error and yaw positioning error on assembly accuracy were also analyzed by FEM. The results show that the assembly can meet the accuracy requirements when the aligning error is smaller than $0.01 \mathrm{~mm}$ and the yaw angle is less than $0.03^{\circ}$. 
A precision press-fit instrument was developed to assemble the parts, and the press-fit displacement and position measuring unit were calibrated and compensated, and the alignment error is less than $10 \mu \mathrm{m}$. Assembly experiments showed that the force-displacement curves all within the reasonable range, and the parallelism deviation and axial positioning deviation of parts are $<0.008 \mathrm{~mm}$ and $<0.04 \mathrm{~mm}$, respectively.

Therefore, the press-fit instrument can achieve high assembly accuracy of small interference fitting parts. The analysis and calibration methods proposed in this paper also have certain reference significance for other assembly operations.

\section{Acknowledgements}

This research work was supported by National Natural Science Foundation of China (U1508211, 51621064) and National Science and Technology Major Project of China (Grant No. 2013ZX04001091).

\section{List of symbols}

\section{$\alpha \quad$ yaw angle}

$S_{u i}$ physical sizes of one pixel of the two CCDs in the

$S_{v i} \quad \mathrm{X}$ and Y directions $(i=1,2)$

$D_{x}, \quad$ origin of coordinates in the CCD coordinates

$D_{y} \quad$ system

$\gamma \quad$ deflection angle between two CCD coordinate axis

$u_{i}, v_{i} \quad$ coordinate values in two CCDs coordinate systems

\section{References}

[1] Sogalad L and Udupa N G S 2009 Load bearing ability of interference-fitted assemblies: a roughness profile analysis. Proc. Inst. Mech. Eng. Part C-J. Eng. Mech. Eng. Sci. 223: 1623-1633

[2] Qzturk F 2010 Finite-element modeling of two-disc shrink fit assembly and an evaluation of material pairs of discs. Proc. Inst. Mech. Eng. Part C-J. Eng. Mech. Eng. Sci. 225: 263-273
[3] Baldanzini N 2004 A general formulation for designing interference-fit joints with elastic-plastic components. $J$. Mech. Des. 126: 737-743

[4] Teng R J, Zhang Y B, Zhou X J and Xu Z N 2012 Mechanical properties and design method of cylindrical interference fit. Chin. J. Mech. Eng. 48: 160-166

[5] Yang G M, Coquille J C, Fontaine J F and Lambertin M 2002 Contact pressure between two rough sourfaces of cylindrical fit. J. Mater. Process. Technol. 3(5): 490-497

[6] Zhandarov S and Mader E 2014 An alternative method of determining the local interfacial shear strength from forcedisplacement curves in the pull-out and microbond tests. Int. J. Adhes. Adhes. 55: 37-42

[7] Benuzzi D and Donzella G 2004 Prediction of the press-fit curve in the assembly of a railway axle and wheel. Proc. Inst. Mech. Eng. Part F-J. Rail Rapid Transit 218: 51-65

[8] Huang C W, Yang G X, Fu N J and Xie J L 2013 Research on fretting fatiuge life of interference fit and its influencing factors. In: International Conference on Mechatronics and Materials Engineering, pp. 293-300

[9] Daniel J, Claas D, Christian S and Sergej F 2011 Automated robot-based separation and palletizing of microcomponents. In: 2011 IEEE International Symposium on Assembly and Manufacturing, pp. 1-6.

[10] Zhang X W, Wang X D, Luo Y, Teng L and Wang X B 2012 Measurement and assembly of trans-scale miniature parts. Nanotechnol. Precis. Eng. 10(4): 342-347

[11] Das A N, Murthy R, Popa D O and Stephanou H E 2012 A multiscale assembly and packaging system for manufacturing of complex micro-nano devices. IEEE Trans. Autom. Sci. Eng. 9(1): 160-170

[12] Xu Z, Wang X D, Cheng X Y, Luo Y and Wang L D 2009 Control tactics and software architectures for micro assembly based on machine vision. Opt. Precis. Eng. 17(4): 819-824

[13] You B, Lou Z F, Luo Y, Xu Y and Wang X D 2015 Prediction of pressing quality for press-fit assembly based on press-fit curve and maximum press-mounting force. Int. J. Aerosp. Eng. 2015, Article ID 823019823019

[14] Timoshenko S and Goodier J N 1951 Theory of elasticity. 2nd ed. New York: McGraw-Hill Book Company, pp. $58-60$

[15] Wang X Y, Lou Z F, Wang X D and Xu C L 2017 A new analytical method for press-fit curve prediction of interference fitting parts. J. Mater. Process. Technol. 250: 16-24 